\title{
Cell-Specific Dual Role of Caveolin-1 in Pulmonary Hypertension
}

\author{
Rajamma Mathew \\ Section of Pediatric Cardiology, Department of Physiology, New York Medical College, Valhalla, NY 10595, USA \\ Correspondence should be addressed to Rajamma Mathew, rajamma_mathew@nymc.edu
}

Received 9 January 2011; Accepted 10 March 2011

Academic Editor: Andrew J. Halayko

Copyright (C) 2011 Rajamma Mathew. This is an open access article distributed under the Creative Commons Attribution License, which permits unrestricted use, distribution, and reproduction in any medium, provided the original work is properly cited.

\begin{abstract}
A wide variety of cardiopulmonary and systemic diseases are known to lead to pulmonary hypertension (PH). A number of signaling pathways have been implicated in $\mathrm{PH}$; however, the precise mechanism/s leading to $\mathrm{PH}$ is not yet clearly understood. Caveolin-1, a membrane scaffolding protein found in a number of cells including endothelial and smooth muscle cells, has been implicated in PH. Loss of endothelial caveolin-1 is reported in clinical and experimental forms of PH. Caveolin-1, also known as a tumor-suppressor factor, interacts with a number of transducing molecules that reside in or are recruited to caveolae, and it inhibits cell proliferative pathways. Not surprisingly, the rescue of endothelial caveolin-1 has been found not only to inhibit the activation of proliferative pathways but also to attenuate $\mathrm{PH}$. Recently, it has emerged that during the progression of $\mathrm{PH}$, enhanced expression of caveolin-1 occurs in smooth muscle cells, where it facilitates cell proliferation, thus contributing to worsening of the disease. This paper summarizes the cell-specific dual role of caveolin-1 in $\mathrm{PH}$.
\end{abstract}

\section{Introduction}

Pulmonary hypertension (PH) is a rare but a devastating disease with high morbidity and mortality rate. The reported prevalence is $15-52$ cases/million and the incidence is thought to be $2.4-7.6$ cases/million/year $[1,2]$. A wide variety of cardiopulmonary diseases, collagen vascular and autoimmune diseases, chronic thromboembolism, HIV, portal hypertension, drug toxicity, and myeloproliferative diseases are known to lead to $\mathrm{PH}$. In primary pulmonary arterial hypertension (PAH), currently labeled as idiopathic $\mathrm{PAH}$, the underlying etiology is not clear and about $6 \%$ of patients in this group have a family history of the disorder $[3,4]$. Multiple signaling pathways and inflammation have been implicated in the pathogenesis of PH. Endothelial dysfunction may be an important triggering factor leading to an imbalance between vasorelaxation and vasoconstriction and deregulation of cell proliferation leading to vascular remodeling and $\mathrm{PH}$ with subsequent cell migration and neointima formation. Loss of bioavailability of nitric oxide $(\mathrm{NO})$ and prostacyclin $\left(\mathrm{PGI}_{2}\right)$ [5-7], upregulation/activation of proliferative molecules such as endothelin-1 (ET1) [8, 9], platelet-derived growth factor (PDGF) [10], serotonin [11], survivin [12], cyclin D1 [13], tyrosine-phosphorylated signal transducer and activator of transcription 3 (PYSTAT3) [14, 15], RhoA/Rho kinase [16, 17], and antiapoptotic molecules such as Bcl2 and $\mathrm{Bcl}-\mathrm{xL}[18,19]$ have been reported in $\mathrm{PH}$. In addition, increased elastase activity [20] and increased production of matrix metalloproteinase 2 (MMP2) [21] occur in PH. Recent studies have shown a strong link between heterozygous germline mutations in bone morphogenic protein receptor type II (BMPRII), a member of TGF $\beta$ superfamily and pulmonary arterial hypertension (PAH). Mutation of BMPRII has been reported in $70 \%$ of heritable $\mathrm{PAH}, 26 \% \mathrm{IPAH}$, and $6 \%$ of patients with congenital heart defect and associated PAH. However, only about $20 \%$ of people with this mutation develop PAH [22-25], indicating that environmental and/or other genetic factors may be involved in the development of the disease. Furthermore, recent studies have shown reduction in the expression of BMPRII protein in both monocrotaline (MCT) and the hypoxia models of $\mathrm{PH}[26,27]$. In addition, mutations of activin-like receptor kinase 1 (ALK1) and endoglin, both belonging to TGF $\beta$ superfamily, have been reported in patients with hereditary hemorrhagic telangiectasia, and some of these patients develop PAH [28].

Regardless of the underlying etiology, the main features are endothelial dysfunction, impaired vascular relaxation 
response, deregulated cell proliferation and impaired apoptosis, vascular remodeling, narrowing of the lumen, elevated PA pressure, and right ventricular hypertrophy with subsequent right heart failure and premature death. Despite major advances in the understanding of the disease process, a cure is not yet in sight. Current therapy has improved the quality of life but has not had a significant effect on the mortality rate [29]. Loss of endothelial caveolin-1, a cell membrane protein is well documented in experimental and clinical forms of $\mathrm{PH}[13,14,30]$. Recent studies indicate that in addition to the loss of endothelial caveolin-1, there is enhanced expression of caveolin-1 in smooth muscle cells with proliferative activity and subsequent neointima formation $[31,32]$. Thus, caveolin-1 may play a key role in the pathogenesis of $\mathrm{PH}$, and its activity may depend on cell type and the disease stage.

\section{Caveolin-1 and Caveolae}

Caveolae are 50-100 nm flask-shaped invaginations rich in cholesterol and sphingolipids was described by Palade and Yamada in 1950s [33, 34]. Caveolae are a subset of lipid rafts found on the plasmalemmal membranes of a variety of cells including endothelial, smooth muscle, epithelial cells, and fibroblasts. One of the major functions of caveolae is to serve as a platform and to compartmentalize the signaling molecules that reside in or are recruited to caveolae. Caveolae are also involved in transcytosis, endocytosis, and regulation of cell proliferation, differentiation, and apoptosis via a number of diverse signaling pathways. Three isoforms of caveolin gene family have been identified. Caveolin-3 is a muscle-specific gene found primarily in skeletal and cardiac myocytes. Caveolin-2 not only colocalizes with caveolin1 but also requires caveolin-1 for membrane localization. Caveolin-1 (22 kD) is the major constitutive protein of caveolae that interacts and regulates several proteins including Src family of kinases, G-proteins ( $\alpha$ subunits), G proteincoupled receptors, $\mathrm{H}$-Ras, PKC, eNOS, integrins, and growth factor receptors such as VEGF-R and EGF-R. Caveolin-1 stabilizes these signaling proteins, and generally, proteinprotein interaction with caveolin-1 exerts negative regulation of the target protein within caveolae; these interactions occur through caveolin-1-scaffolding domain (CSD, residue 82101 in caveolin-1) [35-41]. Major ion channels such as $\mathrm{Ca}^{2+}$ dependent potassium channels and voltage-dependent $\mathrm{K}^{+}$ channels $(\mathrm{Kv} 1.5)$ and a number of molecules responsible for $\mathrm{Ca}^{2+}$ handling such as inositol triphosphate receptor $\left(\mathrm{IP}_{3} \mathrm{R}\right)$, heterodimeric GTP-binding protein, $\mathrm{Ca}^{2+}$ ATPase, and several transient receptor potential channels localize in caveolae and interact with caveolin-1. In SMC, caveolin1 regulates $\mathrm{Ca}^{2+}$ entry and enables vasoconstriction. The localization of $\mathrm{Ca}^{2+}$-regulating proteins in caveolae and the proximity to sarcoplasmic reticulum is indicative of an important role for caveolae/caveolin-1 for $\mathrm{Ca}^{2+}$ homeostasis [42-44]. RhoA interacts directly with caveolin-1, and the translocation of RhoA to caveolae is required for myogenic tone. The CSD peptide of caveolin-1 has been shown to inhibit the agonist-induced redistribution of RhoA and PKC$\alpha$ [45-47]. In addition, caveolin-1 ablation attenuates both pressure and agonist-induced vasoconstriction [48]. Thus, caveolae/caveolin-1 plays a complex and important role in regulating $\mathrm{Ca}^{2+}$ homeostasis.

Endothelial cells (EC) are thought to have one of the highest levels of caveolin-1 [36]. One of the major functions of endothelial cells is to maintain vascular tone and structure; in addition, endothelial cell layer forms an important interface between circulating blood and vascular smooth muscle cells. Nitric oxide (NO), endothelium-derived hyperpolarizing factor (EDHF), and $\mathrm{PGI}_{2}$ are potent vasodilators and antimitogenic factors produced by endothelial cells to maintain vascular health. Sustained $\mathrm{Ca}^{2+}$ entry into EC regulated by caveolin-1 is required for the activation of NO, PGI2, and EDHF. Importantly, caveolin-1 deficiency impairs $\mathrm{Ca}^{2+}$ entry, thus caveolin-1 has an impact on the activation of these vasoactive factors [49]. Endothelial NO synthase (eNOS) catalyzes conversion of L-arginine to NO. For optimum activation, eNOS is targeted to caveolae. Although it is negatively regulated by caveolin-1, caveolin1 is crucial for NO-mediated angiogenesis [50-54]. In addition, the downstream effector of $\mathrm{NO}$, soluble guanylate cyclase has been shown to compartmentalize in caveolae to facilitate its activation [55]. Genetic deletion of caveolin1 has been shown to abrogate EDHF-induced hyperpolarization by altering $\mathrm{Ca}^{2+}$ entry, thus highlighting the role of caveolin-1 in EDHF regulation [56]. $\mathrm{PGI}_{2}$, a potent vasodilator produced by EC is formed from arachidonic acid by the enzymatic activity of $\mathrm{PGI}_{2}$ synthase, which also colocalizes with caveolin-1. Unlike eNOS, $\mathrm{PGI}_{2}$ synthase remains enzymatically active even when bound to caveolin1. Colocalization of eNOS and $\mathrm{PGI}_{2}$ synthase and VEGFR2 with caveolin-1 suggests a role for caveolin-1 in angiogenesis signaling pathways [57]. Furthermore, VEGFR2 activation has been shown to be impaired in endothelial cells from caveolin-1 knockout (KO) mice, further supporting a role for caveolin-1 in VEGF-induced signaling $[52,58]$.

Recent studies have shown that caveolae and caveolin-1 may serve as mechanosensers and/or transducers in arterial responses to alterations in blood flow. Vascular endothelial cells subjected to blood flow-induced shear stress transform mechanical stimuli into biological signaling known as mechanotransduction. Mechanosensing by endothelial cells results in the activation of MAPK/ERK, Akt, and eNOS pathways, thus preventing apoptosis and facilitating vasodilation. Furthermore, impaired flow-mediated vasoldilation in caveolin-1 $\mathrm{KO}$ mice is rescued by reconstitution of caveolin-1. Interestingly, poor activation of ERK $1 / 2$ and Akt in EC with low caveolin-1 is thought to be due to impaired VEGFR2 signaling [59, 60]. Thus, caveolin-1 and caveolae are essential for maintaining normal function of blood vessels.

Caveolin-1, also known as a tumor-suppressor factor, inhibits a number of proliferative pathways. Downregulation of caveolin-1 has been shown to lead to hyperactivation of MAPK/ERK pathway. In caveolin-1 KO mice, observed cell hyperproliferation has been attributed to MAPK/ERK signaling pathway. Interestingly, caveolin-1 is negatively regulated by MAPK/ERK pathway [61-63]. Caveolin-1 regulates apoptosis in several cell types. It promotes cell-cycle arrest via 
a $p 53 / p 21^{\text {wafl/cip1 }}$-dependent mechanism. It has been further shown that caveolin-1 facilitates apoptosis via suppressing survivin [64-66]. Caveolin-1 inhibits PDGF receptor signaling and is capable of transforming PDGF-induced proliferative signals into death signals $[67,68]$. Caveolin-1 also functions as an immunomodulator. It modulates inflammatory processes via its regulatory effect on eNOS, and depending on the cell type and possibly the disease, the effect can be positive or negative. In addition, caveolin-1 inhibits and degrades inflammatory and proneoplastic protein COX2 to maintain it at the homeostatic level, and caveolin-1 regulation of TGF- $\beta$ signaling and modulates several cellular processes including differentiation and migration. TGF- $\beta 1$ receptor activin like receptor kinase (ALK) 1 colocalizes with caveolin-1 and both proteins regulate angiogenesis [69-76].

Thus, caveolin-1 regulates and interacts directly or indirectly with a number of signaling molecules implicated in PH. Therefore, there is a reason to believe that the alterations in endothelial cell membrane integrity and caveolin1 may have a profound effect on the development and the progression of pulmonary vascular disease.

\section{Endothelial Caveolin-1 in Pulmonary Hypertension}

3.1. Disruption of Endothelial Cell Membrane and Loss of Caveolin-1. Loss of endothelial caveolin-1 has been reported in clinical and experimental forms such as monocrotaline (MCT) and myocardial infarction models of $\mathrm{PH}[13,14,30]$. The MCT model has been extensively studied to understand the pathogenesis of $\mathrm{PH}$. A single subcutaneous injection of MCT in rats injures endothelial cells within $24-48 \mathrm{hrs}$ and PH is observed at 10-14 days after MCT. In this model the disruption of endothelial caveolae associated with progressive loss of caveolin-1 occurring as early as $48 \mathrm{hrs}$ after MCT, is a major feature seen before the onset of $\mathrm{PH}$. In addition to the loss of caveolin-1, there is reduction in the expression of other endothelial cell membrane proteins known to colocalize with caveolin-1 such as Tie2 (endotheliumspecific tyrosine kinase receptor of angiopoietin 1), platelet endothelial cell adhesion molecule (PECAM) 1, and both subunits of soluble guanylate cyclase $[14,19]$. Importantly, the loss of caveolin-1 is associated with reciprocal activation of signal transducer and activator of transcription (STAT) 3 to PY-STAT3, known to be preferentially activated by downstream effectors of proinflammatory cytokine IL6/gp130 signaling pathway. In addition, the expression of Bcl-xL is increased simultaneously with the activation of PY-STAT3. PY-STAT3 plays a critical role in cell growth, inhibition of apoptosis, survival, and in immune function and inflammation. Persistent phosphorylation of STAT3 has been reported in a number of primary tumors, and activation of STAT3 signaling confers resistance to apoptosis, $[13,14$, $19,77]$. Some of the downstream effectors of PY-STAT3 are survivin and Bcl-xL (antiapoptotic factors), and cyclin D1 (cell-cycle regulator). All these factors have been shown to be upregulated in PH. Importantly, activation of PY-STAT3 has been observed in endothelial cells obtained from patients with idiopathic PAH [15]. RhoA/Rho kinase activation is well established in PH, and interestingly, Rho GTPases is required for STAT3 activation, and Rho GTPases-mediated cell proliferation and migration occur via STAT3 $[17,78]$. Caveolin-1 functions as a suppressor of cytokine signaling (SOCS) 3 and inhibits PY-STAT3 activation [79]. Therefore, it is not surprising that the rescue of endothelial caveolin1 not only inhibits STAT3 activation but also restores the endothelial cell membrane integrity and attenuates MCTinduced $\mathrm{PH}$ and vascular remodeling [80-82]. These results underscore the importance of endothelial cell membrane integrity and the expression of endothelial caveolin-1 in maintaining vascular health.

Studies with caveolin-2 KO mice have shown pulmonary defects such as alveolar wall thickening and increased cell proliferation similar to what has been reported in caveolin-1 KO mice. Unlike caveolin-1 KO, caveolin-2 KO has no effect on vascular reactivity, nor does it participate in the formation of caveolae. Interestingly, in the MCT and myocardial infarction models of PH, in addition to loss of caveolin-1, caveolin2 loss occurs, and the rescue of caveolin-1 attenuates $\mathrm{PH}$ and also restores caveolin-2 expression [13, 81, 83]. Since caveolin-2 requires caveolin- 1 for its transport to the membrane surface, caveolin-2 loss may accompany the caveolin1 loss in these models of PH. It is likely that caveolin-2 participates with caveolin-1 in pulmonary vascular health and disease. It is not clear what independent role caveolin2 might have in the pathogenesis of PH. Further studies are warranted to examine the specific role of caveolin-2 in $\mathrm{PH}$.

3.2. Perturbation of Endothelial Cell Membrane and Dysfunction of Caveolin-1. PH is an important cause of heart failure and increased mortality in patients suffering from chronic lung diseases associated with alveolar hypoxia [84]. Hypoxia induces pulmonary vasoconstriction and vascular remodeling leading to $\mathrm{PH}$. In hypoxia-induced $\mathrm{PH}$, similar to the MCT model, low bioavailability of NO, low basal and agonist-induced cGMP levels, and impaired endotheliumdependent NO-mediated relaxation responses in pulmonary arteries have been reported [85-87]. Interestingly, BH4 or Larginine administration does not improve eNOS dysfunction [85]. However, unlike the MCT model, in hypoxia-induced $\mathrm{PH}$, there is no reduction in caveolin-1 expression. Murata et al. [85] have further shown that in pulmonary arteries from rats with hypoxia-induced $\mathrm{PH}$, eNOS forms a tight complex with caveolin-1 and becomes dissociated from HSP90 and calmodulin, resulting in eNOS dysfunction. In addition, the long-term effect of prenatal hypoxia results in impaired endothelium-dependent and NO-mediated relaxation responses coupled with increased caveolin-1 and eNOS association [88]. Interestingly, hypoxia-induced $\mathrm{PH}$ and pulmonary endothelial cells exposed to hypoxia exhibit hyperactivation of PY-STAT3 [89]. Hypoxia-inducible factor (HIF) $1 \alpha$ is thought to play a significant role in hypoxiainduced hyperplasia of SMC [90]. STAT3 plays a significant role in stabilizing HIF $1 \alpha$, and its interaction with HIF $1 \alpha$ mediates transcriptional activation of vascular endothelial growth factor (VEGF) promoter. Targeting STAT3 blocks HIF $1 \alpha$ and VEGF, thus modulating proliferation and angiogenesis $[91,92]$. These results strongly suggest that PY-STAT3 
may be an important regulator of VSMC proliferation in $\mathrm{PH}$ irrespective of the underlying etiology.

Since caveolin-1 has been shown to inhibit PY-STAT3 activation [79-81], the activation of PY-STAT3 in hypoxiainduced $\mathrm{PH}$ despite the unaltered expression of caveolin-1 protein strongly suggests that caveolin-1 is dysfunctional and has lost its inhibitory function. Furthermore, within $24 \mathrm{hr}$ exposure to hypoxia, bovine pulmonary artery endothelial cells reveal caveolin-1 and eNOS complex formation accompanied by PY-STAT3 activation (Figures $1(\mathrm{a})$ and $1(\mathrm{~b})$ ). These results indicate that the tight complex formation of caveolin-1 and eNOS in hypoxia-induced $\mathrm{PH}$ renders both eNOS and caveolin-1 dysfunctional. In this context, it is worth noting that statins protect eNOS function in hypoxiainduced PH. The major effect of statins is reported to be the uncoupling of eNOS/caveolin-1 complex, thus freeing eNOS for activation. This effect on eNOS is not accompanied with lowering of cholesterol [93]. It is likely that the statins disrupt the tight cavolin-1/eNOS coupling resulting from hypoxiainduced perturbation of endothelial cell membrane, thus restoring antiproliferative properties of caveolin-1 and $\mathrm{NO}$ production by eNOS. Unlike the MCT model, hypoxia does not appear to cause physical disruption of EC membrane but causes perturbation of the endothelial cell membrane and leading to "mislocalization" of caveolin-1 and eNOS.

\section{Progressive Endothelial Cell Damage and Enhanced Expression of Caveolin-1 in SMC in Pulmonary Hypertension}

Juxtaposition of EC and SMC facilitates crosstalk and coregulation and EC protects SMC from blood elements and direct shear stress. Our studies with experimental and clinical $\mathrm{PH}$ show that inflammation and drug-induced injury disrupt endothelial cell membrane integrity leading to the loss of endothelial caveolin-1. The endothelial damage is progressive resulting in the loss of cytosolic proteins, such as HSP90, Akt, $\mathrm{I} \kappa \mathrm{B} \alpha$, eNOS and subsequently the loss of von Willebrand factor (vWF) $[14,19,32]$. vWF, synthesized by endothelial cells is stored in Weibel Palade bodies within the cell; therefore, the loss of $\mathrm{vWF}$ is indicative of an extensive endothelial damage or loss. Importantly, increased plasma levels of vWF and circulating endothelial cells are markers of poor prognosis in $\mathrm{PAH}[18,94,95]$. Enhanced expression of caveolin-1 in SMC is seen only in the arteries exhibiting vWF loss [32], and interestingly, a loss/apoptosis of endothelial cells is thought to trigger SMC proliferation [96].

The number of caveolae in SMC are said to be less than half that of EC [97]. Recent studies have shown robust expression of caveolin-1 in SMC in PAH, in addition to the loss of endothelial caveolin-1 [31, 32]. Following immunosuppressant therapy-induced endothelial damage, a significant loss of endothelial caveolin-1 and vWF was shown to be associated with robust expression of caveolin-1 in SMC with subsequent neointima formation [32]. Interestingly, in patients with chronic obstructive pulmonary disease, expression of caveolin-1 in SMC was seen only in the presence of $\mathrm{PH}$ [98]. Smooth muscle cells isolated from patients with idiopathic PAH exhibit not only enhanced caveolin-1 expression but also altered $\mathrm{Ca}^{2+}$ handling, increased cytosolic $\left[\mathrm{Ca}^{2+}\right]_{\mathrm{i}}$ and increased DNA synthesis. Increased $\left[\mathrm{Ca}^{2+}\right]_{\mathrm{i}}$ is a trigger for DNA synthesis and cell proliferation [31]. Caveolin-1 is considered to play an important role in the regulation of vascular SMC in receptor-mediated signaling [99]. Caveolin-1 regulates mitogenic signaling and $\mathrm{Ca}^{2+}$ entry in SMC. Normally, caveolin-1 keeps mitogens inactive in caveolae, but under increased mechanical stress/strain, caveolin-1 translocates from caveolae to noncaveolar sites within the plasma membrane of cultured SMC and translocated caveolin-1 triggers cell-cycle progression and cell proliferation $[100,101]$. The extensive endothelial damage, as described in the preceding section, may result in a breach in the endothelial layer, thus exposing SMC to high cyclic pressure with consequent enhanced expression of caveolin-1 in SMC and possible translocation from caveolae. Interestingly, caveolin-1 requires cavin-1 (one of the cavin protein family also known as polymerase 1 and transcript release factor) for caveolae formation. Recent in vitro studies show that cells (murine lung endothelial and HeLa cells) exposed to mechanical stress reveal reduced caveolin-1/cavin-1 interaction, disappearance of caveolae, and increased expression of caveolin-1 at the plasma membrane [102, 103]. It is tempting to postulate that in $\mathrm{PH}$, the observed enhanced expression of caveolin-1 in SMC may in part be related to the reduction in caveolin-1/cavin-1 interaction and loss of caveolae during exposure to pulsatile shear stress. Further studies are required to address caveolin-1/cavin-1 interaction in SMC in PH.

SMC migration, matrix degradation, and remodeling leading to neointima formation are essential aspects of $\mathrm{PH}$. Matrix metalloproteinases (MMP); especially, the activation of MMP2 is considered a critical step in the migration of SMC through the basement barrier. MMP2 belongs to a family of zinc-dependent endopeptidases called MMPs, involved in matrix degrading processes. MMP2 has been implicated in vascular remodeling and plays an important role in cell migration, thus contributing to neointima formation. Not surprisingly, increased expression and activity of smooth muscle cell MMP2 has been reported in idiopathic PAH. Importantly, MMP2 and its physiologic activator MT1MMP colocalize in caveolae and are negatively regulated by caveolin-1 [21, 104-106]. This suggests that the exposure of SMC to increased shear stress may translocate caveolin-1 from caveolae to other plasma membrane sites, thus losing its inhibitory activity on MT1-MMP and MMP2 and facilitating cell migration via MMP2. In support of this view, it has been shown that the caveolin-1 re-expression in tumor cells inhibited MMP activation and function thereby preventing cell migration [107]. In vascular SMC, the localization of BMPRII to caveolae and binding with caveolin-1, required for efficient signal transduction and disruption of caveolin-1 and BMPRII interaction negatively affects BMP2-dependent SMAD phosphorylation [108]. Thus, the localization of caveolin-1 in caveolae may be of paramount importance for its activity.

Acute respiratory syndrome (ARDS) is comprised of increased pulmonary vascular permeability and pulmonary 

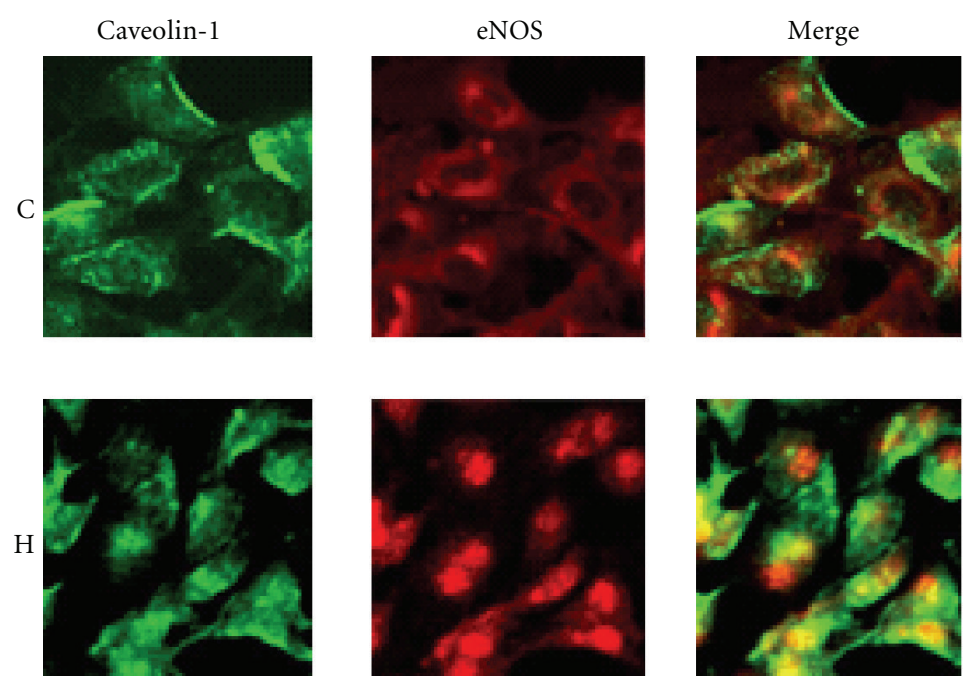

(a)
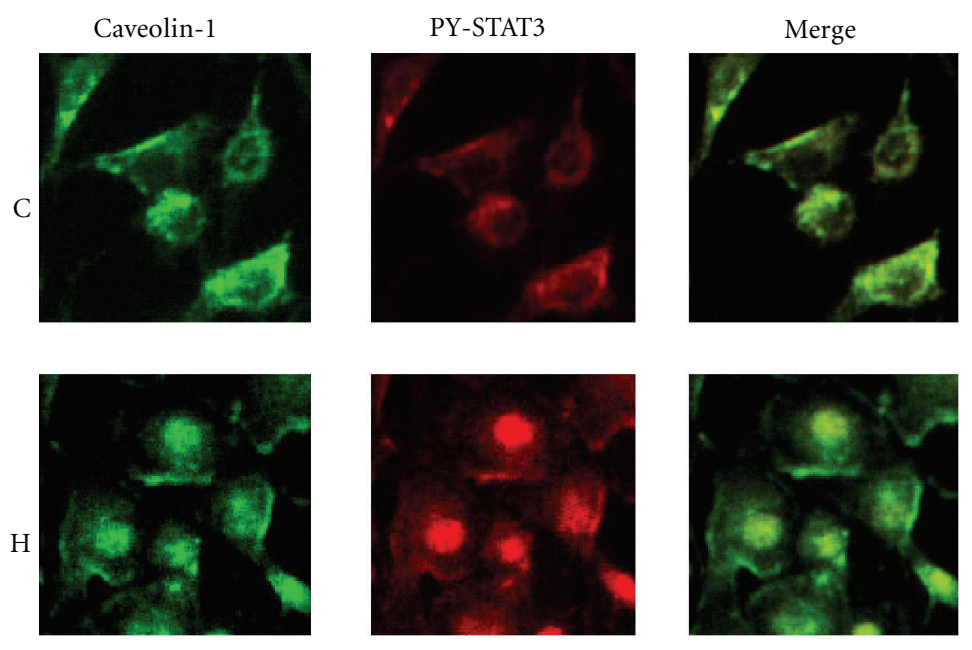

(b)

FIGURE 1: Bovine pulmonary artery endothelial cells (BPAEC) after $24 \mathrm{hr}$ exposure to hypoxia ( $\mathrm{H}, 5 \% \mathrm{O}_{2}$ ) and in normoxia (C). (a) During hypoxia the expression of caveolin-1 (green) and eNOS (red) appear increased and they form a complex. (b) PY-STAT3 (red) activation is observed after exposure to hypoxia.

edema associated with hypoxemia and carbon dioxide retention, caused by a variety of pulmonary and systemic insults and drug toxicity. Endothelial injury is a critical underlying feature resulting in the disruption of alveolarcapillary membrane and vascular fluid leak. The reported incidence is about $2.2-16 / 100,000$ with a mortality rate of about $40 \%$. Incidence of $\mathrm{PH}$ is as high as $92 \%$ in patients with ARDS, severe and moderated being 7\% and 76\% respectively [109-111]. A recent case report [32] has shown that within 2 months of developing ARDS, lung biopsy revealed loss of endothelial caveolin-1 in several arteries without any evidence of $\mathrm{PH}$. This is similar to the observation in the MCT model, where the progressive loss of endothelial caveolin-1 occurs before the onset of $\mathrm{PH}[19,80]$. The second patient developed severe $\mathrm{PH}$ despite having clinically recovered from
ARDS two years earlier. Importantly, the loss of vWF was associated with robust expression of caveolin-1 in SMC with subsequent neointima formation [32]. Interestingly, increased plasma vWF antigen is an independent marker of poor prognosis in acute lung injury and is associated with high mortality, similar to what has been reported in $\mathrm{PAH}$ [95, 112]. Thus, the loss of endothelial cell membrane integrity, and resulting caveolin-1 loss, directly or indirectly facilitates vascular leak and has the potential to initiate pulmonary vascular disease. Progressive endothelial damage as indicated by loss of vWF and enhanced expression of caveolin-1 in SMC may portend worsening $\mathrm{PH}$.

It is worth noting that caveolin-1, a marker of mature and contractile SMC, keeps SMC in quiescence. It modulates $\mathrm{Ca}^{2+}$-regulatory molecules, increases $\mathrm{Ca}^{2+}$ mobilization and 


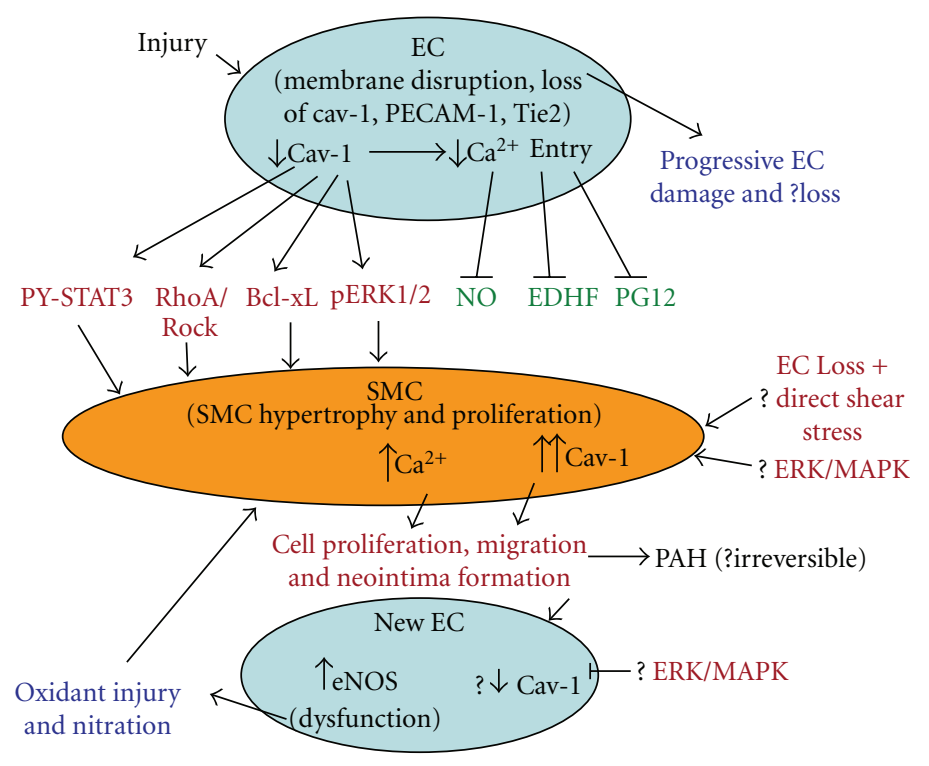

Figure 2: This figure depicts the proposed model of PH (\#1). Injury to EC results in progressive loss of endothelial caveolin-1, loss of vasodilators, and the activation of proliferative and anti-apoptotic pathways leading to $\mathrm{PH}$. EC disruption is progressive resulting in further loss of multiple proteins and possibly the loss of EC. Extensive damage/loss of EC exposes SMC to direct shear stress leading to enhanced expression of caveolin-1 which participates in further cell proliferation and cell migration resulting in neointima formation. Newly formed EC in neointima express increased eNOS; possibly low caveolin-1 expression in these cells may in part be responsible for the observed dysfunctional eNOS. The resulting oxidant/nitration injury further influences $\mathrm{PH}$ adversely.

facilitates contractile responses to agonists. In addition, interaction of caveolin-1 and RhoA is critical for pressureinduced myogenic tone in resistance arteries. Therefore, it is not surprising that the arteries from caveolin-1 KO mice develop poor myogenic tone in response to pressure. Caveolin-1 also prevents proliferative activity. It inhibits receptor and nonreceptor tyrosine kinases by sequestering them to caveolae and prevents cell proliferation. Furthermore, disruption or ablation of caveolin-1 in airway and vascular SMC show increased cell proliferation [113-115]. Thus, caveolin-1 is essential for normal functioning of SMC.

Taken together, our studies and published reports, it appears that injury to EC (shear stress, drug toxicity, inflammation) results in (a) a progressive loss of endothelial caveolin-1, (b) impaired $\mathrm{Ca}^{2+}$ entry into EC resulting in reduced production of vasodilators, and (c) reciprocal activation of mitogenic signaling pathways leading to vascular cell proliferation, medial wall thickening, and $\mathrm{PH}$. It is possible that $\mathrm{PH}$ at this stage may be reversible. Progressive EC damage results in further loss of proteins including eNOS. As the disease progresses, extensive EC damage/loss occurs followed by enhanced expression of cav-1 in SMC, where cav-1 facilitates cell proliferation and migration leading to neointima formation. It is likely that translocated caveolin1 in SMC not only loses its ability to inhibit proliferative pathways but also switches from being antiproliferative to proproliferative that may eventually lead to SMC phenotype change from contractile to synthetic type. Recent studies indicate that there is increased expression of eNOS in neointimal EC, but eNOS is dysfunctional, resulting in oxidant/nitration injury, thus further aggravating $\mathrm{PH}$ as outlined in Figure 2. In contrast, perturbation of EC in hypoxia model of PH results in a tight complex formation of caveolin1 and eNOS leading to dysfunction of both caveolin-1 and eNOS. The end results are impaired availability of NO, the activation of proliferative pathways, vascular remodeling, and $\mathrm{PH}$. It is worth noting that there is no loss of eNOS or caveolin-1 protein in this model (Figure 3).

\section{Caveolin-1 Knockout (KO) Mice and Pulmonary Hypertension}

Studies conducted with caveolin-1 KO mice have provided valuable information regarding the function of caveolin-1 in pulmonary vascular health and disease. Caveolin-1 KO mice are viable and fertile, but with significantly shortened life span. Embryonic fibroblasts taken from these animals show increased capacity for cell proliferation, and arterial SMC lacking caveolin-1 display abnormalities in proliferation both in vivo and in vitro. Furthermore, these mice manifest hypercellular lung phenotypes, cardiomyopathy, systemic vasculopathy, and a propensity to develop PH [115-120]. In caveolin-1 KO mice there is a global loss of caveolin-1 associated with hyperactivation of eNOS, increased cGMP production, and re-expression of endothelial caveolin-1 restores vascular and cardiac pathology and dysfunction [121]. However, there is a distinct difference between caveolin-1KO mice model of $\mathrm{PH}$ and the MCT model visà-vis eNOS expression and function. In the latter model, MCT injures pulmonary endothelial cells within the first 


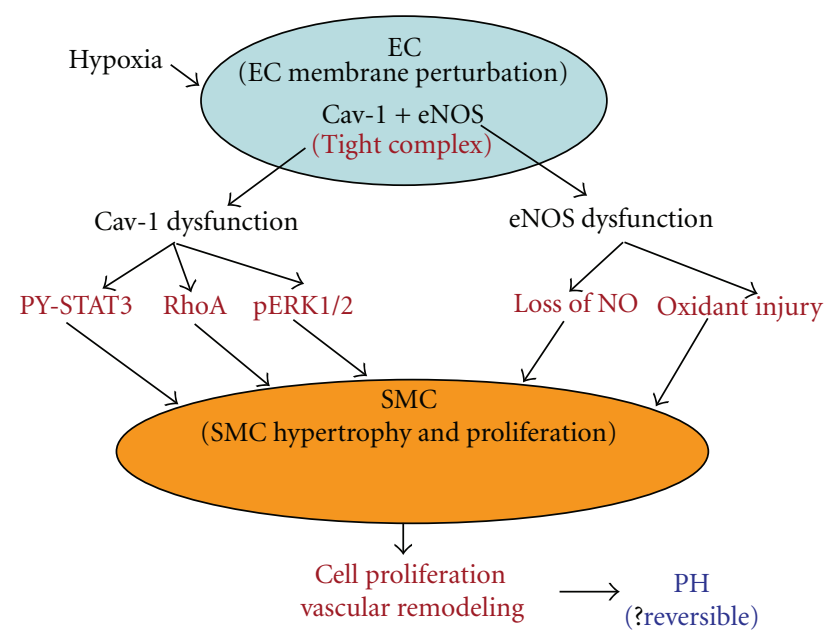

FIgURE 3: This figure depicts the proposed model of PH (\#2). Hypoxia causes perturbation of endothelial cell membrane, and caveolin1 and eNOS form a tight complex rendering both molecules dysfunctional. eNOS dysfunction function leads to impaired NO availability and superoxide generation, and dysfunctional caveolin1 loses its ability to inhibit proliferative pathways resulting in the activation of mitogenic pathways. The end results are pulmonary vascular remodeling and $\mathrm{PH}$.

pass through the lungs resulting in progressive disruption of endothelial cell membrane and a loss of endothelial caveolin1 with subsequent endothelial dysfunction, vascular remodeling, and PH. At 2 weeks after MCT with the onset of $\mathrm{PH}$, there is impaired endothelium-dependent, NO-mediated pulmonary vascular relaxation response. At this stage, there is a loss of cytosolic proteins such as HSP90 and Akt, both required for eNOS activation. However, eNOS protein expression is relatively well preserved, but there is transient uncoupling of eNOS as indicated by increased superoxide generation, reduction in sulfhydril levels, cGMP levels, and impaired endothelium-dependent NO-mediated vascular relaxation responses $[9,79,85]$. By 3 and 4 wks after MCT, the level of eNOS protein is significantly reduced and the superoxide generation returns to normal levels $[9,19,122]$.

It has recently been suggested that the hyperactivation of eNOS subsequently leading to PKG nitration may be responsible for $\mathrm{PH}$ in the caveolin-1 KO mice. Interestingly, treatment with superoxide scavenger or the inhibition of eNOS reverses $\mathrm{PH}$, supporting the view [123]. These authors have further shown increased eNOS activation, PKG nitration and reduced caveolin-1 in the lungs from patients with idiopathic PAH [123]. Furthermore, in an earlier report, increased expression of eNOS in plexiform lesions in both primary and secondary PH was described [124]. In contrast, several other studies show loss of eNOS in the lungs from patients with idiopathic $\mathrm{PAH}$, and $\mathrm{PH} / \mathrm{PAH}$ associate with a variety of diseases such as congenital heart defect, rheumatic heart disease, cirrhosis, and systemic lupus erythematosis $[125,126]$. These observed differences in eNOS expression may depend on the stage of disease in a given lung section, because the disease does not progress uniformly.
Importantly, it has recently been shown that severe angioproliferative PAH is associated with initial endothelial cell apoptosis followed by the appearance of apoptosis-resistant proliferating endothelial cells [96], and these proliferative EC in neointima have reduced expression of caveolin-1 [30]. Based on these clinical and experimental studies, one could postulate that the initial endothelial injury which is progressive results in extensive endothelial cell damage and/or loss leading to a loss of eNOS protein expression. As the apoptosis-resistant endothelial cells proliferate, increased eNOS expression coupled with low caveolin-1 expression in these cells may lead to eNOS dysfunction. Further studies are required to elucidate these observed differences in the expression of eNOS in $\mathrm{PH}$.

\section{Nitric Oxide and Pulmonary Hypertension}

Impaired NO bioavailability is the hallmark of $\mathrm{PH}$. NO is produced from L-arginine via catalytic activity of eNOS. NO released from EC activates soluble guanylate cyclase to produce cGMP, which facilitates $\mathrm{Ca}^{2+}$ uptake into intracellular $\mathrm{Ca}^{2+}$ stores, thereby lowering $\left[\mathrm{Ca}^{2+}\right]_{\mathrm{i}}$ and inducing vascular relaxation. In addition to the vascular relaxation function, NO/cGMP pathway regulates SMC proliferation and migration, cellular responses to inflammation, controls the concentrations of antioxidants, and modulates apoptosis. Inhibition of NO synthesis results in increased pulmonary vascular thickening and administration of $\mathrm{NO}$ attenuates $\mathrm{PH}$. Interestingly, treatment with $\mathrm{NO}$ donor started early in the course of MCT-induced PH prevents caveolin1 disruption and attenuates $\mathrm{PH}$, likely through its antiinflammatory function $[82,127,128]$. Thus, there is a dynamic interrelationship between eNOS and caveolin-1, and impaired caveolin-1/eNOS interaction and function may be an important factor in the pathogenesis of $\mathrm{PH}$.

\section{Dual Role of Caveolin-1}

Loss of caveolin-1 has been shown to induce oncogenic transformation, and the cells become resistant to apoptosis. Furthermore, the introduction of caveolin-1 scaffolding domain inhibits cancer progression. Many oncogenes transcriptionally downregulate caveolin-1 expression. However, caveolin-1 regulation impacts both negatively and positively on several aspects of tumor progression. Caveolin-1 acts as a tumor suppressor in the early stages of cancer, but in late stages it promotes metastasis, multidrug resistance, and portends poor prognosis. Caveolin-1 function is thought to be interdependent on tumor stage and the expression of molecular effectors that may have an impact on its role during tumor progression $[63,129-131]$. Similarly in PH, the switch from an antiproliferative to proproliferative function may depend on alteration in caveolin-1 conformation, localization, cell context, and the stage of the disease.

\section{Concluding Remarks}

Caveolae and caveolin-1 play an important role in pulmonary vascular system. Depending on the type of endothelial injury, the end result is either the loss of caveolin-1 secondary 
to endothelial cell membrane disruption or in endothelial caveolin-1 dysfunction. A classic example of the latter case is hypoxia-induced $\mathrm{PH}$ in which a tight complex formation of caveolin-1/eNOS resulting in dysfunction of both molecules is an important feature. Both these alterations, however, do lead to pulmonary vascular remodeling and PH. Disruption of endothelial cell membrane integrity as in the former case is often progressive leading to extensive EC damage and/or loss with subsequent enhanced expression of caveolin-1 in SMC, which participates in further proliferation, cell migration, and neointima formation. These alterations in caveolin-1 may determine reversibility versus irreversibility of the disease process. Thus, depending on the underlying pathology, cellular involvement, and the stage of the disease, modulation of caveolin-1 function may be considered a therapeutic target in $\mathrm{PH}$.

\section{Acknowledgments}

The author would like to thank Dr. Susan Olson (Department of Biochemistry and Molecular Biology) for the gift of bovine pulmonary artery endothelial cells and Dr. Jing Huang (Department of Pediatrics) for having run the immunofluorescence study.

\section{References}

[1] M. Humbert, O. Sitbon, A. Chaouat et al., "Pulmonary arterial hypertension in France: results from a national registry," American Journal of Respiratory and Critical Care Medicine, vol. 173, no. 9, pp. 1023-1030, 2006.

[2] A. J. Peacock, N. F. Murphy, J. J. V. McMurrey, L. Caballero, and S. Stewart, "An epidemiological study of pulmonary arterial hypertension," European Respiratory Journal, vol. 30, no. 1, pp. 104-109, 2007.

[3] G. Simonneau, I. M. Robbins, M. Beghetti et al., "Updated clinical classification of pulmonary hypertension," Journal of the American College of Cardiology, vol. 54, no. 1, pp. S43S54, 2009.

[4] S. Rich, D. R. Dantzker, S. M. Ayres et al., "Primary pulmonary hypertension. A national prospective study," Annals of Internal Medicine, vol. 107, no. 2, pp. 216-223, 1987.

[5] A. T. Dinh Xuan, T. W. Higenbottam, C. Clelland, J. PepkeZaba, G. Cremona, and J. Wallwork, "Impairment of pulmonary endothelium-dependent relaxation in patients with Eisenmenger's syndrome," British Journal of Pharmacology, vol. 99, no. 1, pp. 9-10, 1990.

[6] R. Mathew, E. S. Gloster, T. Sundararajan, C. I. Thompson, G. A. Zeballos, and M. H. Gewitz, "Role of inhibition of nitric oxide production in monocrotaline-induced pulmonary hypertension," Journal of Applied Physiology, vol. 82, no. 5, pp. 1493-1498, 1997.

[7] R. M. Tuder, C. D. Cool, M. W. Geraci et al., "Prostacyclin synthase expression is decreased in lungs from patients with severe pulmonary hypertension," American Journal of Respiratory and Critical Care Medicine, vol. 159, no. 6, pp. 1925-1932, 1999.

[8] A. Giaid, M. Yanagisawa, D. Langleben et al., "Expression of endothelin-1 in the lungs of patients with pulmonary hypertension," The New England Journal of Medicine, vol. 328, no. 24, pp. 1732-1739, 1993.
[9] R. Mathew, G. A. Zeballos, H. Tun, and M. H. Gewitz, "Role of nitric oxide and endothelin-1 in monocrotaline-induced pulmonary hypertension in rats," Cardiovascular Research, vol. 30, no. 5, pp. 739-746, 1995.

[10] R. T. Schermuly, E. Dony, H. A. Ghofrani et al., "Reversal of experimental pulmonary hypertension by PDGF inhibition," Journal of Clinical Investigation, vol. 115, no. 10, pp. 28112821, 2005.

[11] R. Dumitrascu, C. Kulcke, M. Kongshoff et al., "Terguride ameliorates monocrotaline induced pulmonary hypertension in rats," European Respiratory Journal, vol. 37, no. 5, pp. 1104-1118, 2011.

[12] M. S. McMurtry, S. L. Archer, D. C. Altieri et al., "Gene therapy targeting survivin selectively induces pulmonary vascular apoptosis and reverses pulmonary arterial hypertension," Journal of Clinical Investigation, vol. 115, no. 6, pp. 14791491, 2005.

[13] J. F. Jasmin, I. Mercier, R. Hnasko et al., "Lung remodeling and pulmonary hypertension after myocardial infarction: pathogenic role of reduced caveolin expression," Cardiovascular Research, vol. 63, no. 4, pp. 747-755, 2004.

[14] R. Mathew, J. Huang, M. Shah, K. Patel, M. Gewitz, and P. B. Sehgal, "Disruption of endothelial-cell caveolin- $1 \alpha / \mathrm{raft}$ scaffolding during development of monocrotaline-induced pulmonary hypertension," Circulation, vol. 110, no. 11, pp. 1499-1506, 2004.

[15] F. A. Masri, W. Xu, S. A. A. Comhair et al., "Hyperproliferative apoptosis-resistant endothelial cells in idiopathic pulmonary arterial hypertension," American Journal of Physiology, vol. 293, no. 3, pp. L548-L554, 2007.

[16] Z. Do.e Z., Y. Fukumoto, A. Takaki et al., "Evidence for Rho-kinase activation in patients with pulmonary arterial hypertension," Circulation Journal, vol. 73, no. 9, pp. 17311739, 2009.

[17] M. Oka, K. A. Fagan, P. L. Jones, and I. F. McMurtry, "Therapeutic potential of RhoA/Rho kinase inhibitors in pulmonary hypertension," British Journal of Pharmacology, vol. 155 , no. 4, pp. 444-454, 2008.

[18] M. Lévy, C. Maurey, D. S. Celermajer et al., "Impaired apoptosis of pulmonary endothelial cells is associated with intimal proliferation and irreversibility of pulmonary hypertension in congenital heart disease," Journal of the American College of Cardiology, vol. 49, no. 7, pp. 803-810, 2007.

[19] J. Huang, J. H. Wolk, M. H. Gewitz, and R. Mathew, "Progressive endothelial cell damage in an inflammatory model of pulmonary hypertension," Experimental Lung Research, vol. 36, no. 1, pp. 57-66, 2010.

[20] C. Ye and M. Rabinovitch, "Inhibition of elastolysis by SC37698 reduces development and progression of monocrotaline pulmonary hypertension," American Journal of Physiology, vol. 261, no. 4, pp. H1255-H1267, 1991.

[21] H. Lepetit, S. Eddahibi, E. Fadel et al., "Smooth muscle cell matrix metalloproteinases in idiopathic pulmonary arterial hypertension," European Respiratory Journal, vol. 25, no. 5, pp. 834-842, 2005.

[22] J. R. Thomson, R. D. Machado, M. W. Pauciulo et al., "Sporadiac primary pulmonary hypertension is associated with germline mutations of the gene encoding BMPR-II, a receptor member of the TGF- $\beta$ family," Journal of Medical Genetics, vol. 37, no. 10, pp. 741-745, 2000.

[23] R. D. Machado, M. A. Aldred, V. James et al., "Mutations of the TGF- $\beta$ type II receptor BMPR2 in pulmonary arterial hypertension," Human Mutation, vol. 27, no. 2, pp. 121-132, 2006. 
[24] J. D. Cogan, M. W. Pauciulo, A. P. Batchman et al., "High frequency of BMPR2 exonic deletions/duplications in familial pulmonary arterial hypertension," American Journal of Respiratory and Critical Care Medicine, vol. 174, no. 5, pp. 590-598, 2006.

[25] K. E. Roberts, J. J. McElroy, W. P. K. Wong et al., "BMPR2 mutations in pulmonary arterial hypertension with congenital heart disease," European Respiratory Journal, vol. 24, no. 3, pp. 371-374, 2004.

[26] L. Long, A. Crosby, X. Yang et al., "Altered bone morphogenetic protein and transforming growth factor- $\beta$ signaling in rat models of pulmonary hypertension. Potential for activin receptor-like kinase-5 inhibition in prevention and progression of disease," Circulation, vol. 119, no. 4, pp. 566576, 2009.

[27] K. Murakami, R. Mathew, J. Huang et al., "Smurfl ubiquitin ligase causes downregulation of BMP receptors and is induced in monocrotaline and hypoxia models of pulmonary arterial hypertension," Experimental Biology and Medicine, vol. 235, no. 7, pp. 805-813, 2010.

[28] R. C. Trembath, J. R. Thomson, R. D. Machado et al., "Clinical and molecular genetic features of pulmonary hypertension in patients with hereditary hemorrhagic telangiectasia," The New England Journal of Medicine, vol. 345, no. 5, pp. 325-334, 2001.

[29] K. R. Stenmark and M. Rabinovitch, "Emerging therapies for the treatment of pulmonary hypertension," Pediatric Critical Care Medicine, vol. 11, no. 2, pp. S85-S90, 2010.

[30] R. O. D. Achcar, Y. Demura, P. R. Rai et al., "Loss of caveolin and heme oxygenase expression in severe pulmonary hypertension," Chest, vol. 129, no. 3, pp. 696-705, 2006.

[31] H. H. Patel, S. Zhang, F. Murray et al., "Increased smooth muscle cell expression of caveolin-1 and caveolae contribute to the pathophysiology of idiopathic pulmonary arterial hypertension," The FASEB Journal, vol. 21, no. 11, pp. 2970 2979, 2007.

[32] R. Mathew, J. Huang, U. S. Katta, U. Krishnan, C. Sandoval, and M. H. Gewitz, "Immunosuppressant-induced endothelial damage and pulmonary arterial hypertension," Journal of Pediatric Hematology/Oncology, vol. 33, no. 1, pp. 55-58, 2011.

[33] G. E. Palade, "Fine structure of blood capillaries," Journal of Applied Physiology, vol. 24, pp. 1424-1436, 1953.

[34] E. Yamada, "The fine structure of the gall bladder epithelium of the mouse," The Journal of Biophysical and Biochemical Cytology, vol. 1, no. 5, pp. 445-458, 1955.

[35] T. M. Williams and M. P. Lisanti, "The caveolin proteins," Genome Biology, vol. 5, no. 3, article 214, 2004.

[36] P. G. Frank, S. E. Woodman, D. S. Park, and M. P. Lisanti, "Caveolin, caveolae, and endothelial cell function," Arteriosclerosis, Thrombosis, and Vascular Biology, vol. 23, no. 7, pp. 1161-1168, 2003.

[37] B. Razani, S. E. Woodman, and M. P. Lisanti, "Caveolae: from cell biology to animal physiology," Pharmacological Reviews, vol. 54, no. 3, pp. 431-467, 2002.

[38] P. Liu, M. Rudick, and R. G. W. Anderson, "Multiple functions of caveolin-1," The Journal of Biological Chemistry, vol. 277, no. 44, pp. 41295-41298, 2002.

[39] A. F. G. Quest, L. Leyton, and M. Párraga, "Caveolins, caveolae, and lipid rafts in cellular transport, signaling, and disease," Biochemistry and Cell Biology, vol. 82, no. 1, pp. 129144,2004
[40] E. J. Smart, G. A. Graf, M. A. McNiven et al., "Caveolins, liquid-ordered domains, and signal transduction," Molecular and Cellular Biology, vol. 19, no. 11, pp. 7289-7304, 1999.

[41] L. J. Pike, "Lipid rafts: bringing order to chaos," Journal of Lipid Research, vol. 44, no. 4, pp. 655-667, 2003.

[42] T. Fujimoto, "Calcium pump of the plasma membrane is localized in caveolae," Journal of Cell Biology, vol. 120, no. 5, pp. 1147-1158, 1993.

[43] D. P. McEwen, Q. Li, S. Jackson, P. M. Jenkins, and J. R. Martens, "Caveolin regulates Kv1.5 trafficking to cholesterolrich membrane microdomains," Molecular Pharmacology, vol. 73, no. 3, pp. 678-685, 2008.

[44] M. Isshiki and R. G. W. Anderson, "Function of caveolae in $\mathrm{Ca}^{2+}$ entry and $\mathrm{Ca}^{2+}$-dependent signal transduction," Traffic, vol. 4, no. 11, pp. 717-723, 2003.

[45] D. Gingras, F. Gauthier, S. Lamy, R. R. Desrosiers, and R. Béliveau, "Localization of RhoA GTPase to endothelial caveolae-enriched membrane domains," Biochemical and Biophysical Research Communications, vol. 247, no. 3, pp. 888-893, 1998.

[46] C. Dubroca, X. Loyer, K. Retailleau et al., "RhoA activation and interaction with caveolin-1 are critical for pressureinduced myogenic tone in rat mesenteric resistance arteries," Cardiovascular Research, vol. 73, no. 1, pp. 190-197, 2007.

[47] M. J. Taggart, "Smooth muscle excitation-contraction coupling: a role for caveolae and caveolins?" News in Physiological Sciences, vol. 16, no. 2, pp. 61-65, 2001.

[48] A. Adebiyi, D. Narayanan, and J. H. Jaggar, "Caveolin-1 assembles type 1 inositol 1,4,5-trisphosphate receptors and canonical transient receptor potential 3 channels into a functional signaling complex in arterial smooth muscle cells," The Journal of Biological Chemistry, vol. 286, no. 6, pp. 43414348, 2011.

[49] T. Murata, M. I. Lin, R. V. Stan, P. M. Bauer, J. Yu, and W. C. Sessa, "Genetic evidence supporting caveolae microdomain regulation of calcium entry in endothelial cells," The Journal of Biological Chemistry, vol. 282, no. 22, pp. 16631-16643, 2007.

[50] J. P. Gratton, J. Fontana, D. S. O’Connor, G. GarcíaCardeña, T. J. McCabe, and W. C. Sessa, "Reconstitution of an endothelial nitric-oxide synthase (eNOS), hsp90, and caveolin-1 complex in vitro: evidence that hsp90 facilitates calmodulin stimulated displacement of eNOS from caveolin1," The Journal of Biological Chemistry, vol. 275, no. 29, pp. 22268-22272, 2000.

[51] O. Feron, F. Saldana, J. B. Michel, and T. Michel, "The endothelial nitric-oxide synthase-caveolin regulatory cycle," The Journal of Biological Chemistry, vol. 273, no. 6, pp. 31253128, 1998.

[52] P. Sonveaux, P. Martinive, J. DeWever et al., "Caveolin-1 expression is critical for vascular endothelial growth factorinduced ischemic hindlimb collateralization and nitric oxidemediated angiogenesis," Circulation Research, vol. 95, no. 2, pp. 154-161, 2004.

[53] C. Griffoni, E. Spisni, S. Santi, M. Riccio, T. Guarnieri, and V. Tomasi, "Knockdown of caveolin-1 by antisense oligonucleotides impairs angiogenesis in vitro and in vivo," Biochemical and Biophysical Research Communications, vol. 276, no. 2, pp. 756-761, 2000.

[54] J. Liu, X. B. Wang, D. S. Park, and M. P. Lisanti, "Caveolin-1 expression enhances endothelial capillary tubule formation," The Journal of Biological Chemistry, vol. 277, no. 12, pp. 10661-10668, 2002. 
[55] A. E. Linder, L. P. McCluskey, K. R. Cole III, K. M. Lanning, and R. C. Webb, "Dynamic association of nitric oxide downstream signaling molecules with endothelial caveolin1 in rat aorta," Journal of Pharmacology and Experimental Therapeutics, vol. 314, no. 1, pp. 9-15, 2005.

[56] J. Saliez, C. Bouzin, G. Rath et al., "Role of caveolar compartmentation in endothelium-derived hyperpolarizing factor-mediated relaxation- $\mathrm{Ca}^{2+}$ signals and gap junction function are regulated by caveolin in endothelial cells," Circulation, vol. 117, no. 8, pp. 1065-1074, 2008.

[57] E. Spisni, C. Griffoni, S. Santi et al., "Colocalization prostacyclin (PGI2) synthase-caveolin-1 in endothelial cells and new roles for PGI2 in angiogenesis," Experimental Cell Research, vol. 266, no. 1, pp. 31-43, 2001.

[58] L. Labrecque, I. Royal, D. S. Surprenant, C. Patterson, D. Gingras, and R. Béliveau, "Regulation of vascular endothelial growth factor receptor-2 activity by caveolin-1 and plasma membrane cholesterol," Molecular Biology of the Cell, vol. 14, no. 1, pp. 334-347, 2003.

[59] J. Yu, S. Bergaya, T. Murata et al., "Direct evidence for the role of caveolin-1 and caveolae in mechanotransduction and remodeling of blood vessels," Journal of Clinical Investigation, vol. 116, no. 5, pp. 1284-1291, 2006.

[60] A. D. van der Meer, M. M. Kamphuis, A. A. Poot, J. Feijen, and J. Vermes, "Lowering caveolin-1 expression in human vascular endothelial cells inhibits signal transduction in response to shear stress," International Journal of Cell Biology, vol. 2009, Article ID 532432, 9 pages, 2009.

[61] F. Galbiati, D. Volonté, J. A. Engelman et al., "Targeted downregulation of caveolin-1 is sufficient to drive cell transformation and hyperactivate the p42/44 MAP kinase cascade," The EMBO Journal, vol. 17, no. 22, pp. 6633-6648, 1998.

[62] T. M. Williams and M. P. Lisanti, "Caveolin-1 in oncogenic transformation, cancer, and metastasis," American Journal of Physiology, vol. 288, no. 3 57-3, pp. C494-C506, 2005.

[63] J. A. Engelman, X. L. Zhang, B. Razani, R. G. Pestell, and M. P. Lisanti, "p42/44 MAP kinase-dependent and -independent signaling pathways regulate caveolin-1 gene expression. Activation of Ras-MAP kinase and protein kinase a signaling cascades transcriptionally down-regulates caveolin-1 promoter activity," The Journal of Biological Chemistry, vol. 274, no. 45, pp. 32333-32341, 1999.

[64] P. Gargalovic and L. Dory, "Cellular apoptosis is associated with increased caveolin-1 expression in macrophages," Journal of Lipid Research, vol. 44, no. 9, pp. 1622-1632, 2003.

[65] F. Galbiati, D. Volonte', J. Liu et al., "Caveolin-1 expression negatively regulates cell cycle progression by inducing $\mathrm{G}_{0} / \mathrm{G}_{1}$ arrest via a p53/p2 $21^{\mathrm{WAF} 1 / \mathrm{Cip} 1}$-dependent mechanism," Molecular Biology of the Cell, vol. 12, no. 8, pp. 2229-2244, 2001.

[66] V. A. Torres, J. C. Tapia, D. A. Rodríguez et al., "Caveolin1 controls cell proliferation and cell death by suppressing expression of the inhibitor of apoptosis protein survivin," Journal of Cell Science, vol. 119, no. 9, pp. 1812-1823, 2006.

[67] M. Yamamoto, Y. Toya, R. A. Jensen, and Y. Ishikawa, "Caveolin is an inhibitor of platelet-derived growth factor receptor signaling," Experimental Cell Research, vol. 247, no. 2, pp. 380-388, 1999.

[68] T. E. Peterson, M. E. Guicciardi, R. Gulati et al., "Caveolin1 can regulate vascular smooth muscle cell fate by switching platelet-derived growth factor signaling from a proliferative to an apoptotic pathway," Arteriosclerosis, Thrombosis, and Vascular Biology, vol. 23, no. 9, pp. 1521-1527, 2003.
[69] R. Zemans and G. P. Downey, "Role of caveolin-1 in regulation of inflammation: different strokes for different folks," American Journal of Physiology, vol. 294, no. 2, pp. L175-L177, 2008.

[70] M. K. Mirza, J. Yuan, X. P. Gao et al., "Caveolin-1 deficiency dampens toll-like receptor 4 signaling through eNOS activation," American Journal of Pathology, vol. 176, no. 5, pp. 2344-2351, 2010.

[71] Y. Jin, S.-J. Lee, R. D. Minshall, and A. M.K. Choi, "Caveolin1: a critical regulator of lung injury," American Journal of Physiology, vol. 300, no. 2, pp. L151-L160, 2011.

[72] M. Bucci, J. P. Gratton, R. D. Rudic et al., "In vivo delivery of the caveolin-1 scaffolding domain inhibits nitric oxide synthesis and reduces inflammation," Nature Medicine, vol. 6, no. 12, pp. 1362-1367, 2000.

[73] G. Hu, R. D. Ye, M. C. Dinauer, A. B. Malik, and R. D. Minshall, "Neutrophil caveolin-1 expression contributes to mechanism of lung inflammation and injury," American Journal of Physiology, vol. 294, no. 2, pp. L178-L186, 2008.

[74] S. F. Chen, J. Y. Liou, T. Y. Huang et al., "Caveolin-1 facilitates cyclooxygenase-2 protein degradation," Journal of Cellular Biochemistry, vol. 109, no. 2, pp. 356-362, 2010.

[75] B. Razani, X. L. Zhang, M. Bitzer, G. Von Gersdorff, E. P. Böttinger, and M. P. Lisanti, "Caveolin-1 regulates transforming growth factor (TGF)- $\beta /$ SMAD signaling through an interaction with the TGF- $\beta$ type I receptor," The Journal of Biological Chemistry, vol. 276, no. 9, pp. 6727-6738, 2001.

[76] J. F. Santibanez, F. J. Blanco, E. M. Garrido-Martin, F. SanzRodriguez, M. A. Del Pozo, and C. Bernabeu, "Caveolin1 interacts and cooperates with the transforming growth factor- $\beta$ type I receptor ALK1 in endothelial caveolae," Cardiovascular Research, vol. 77, no. 4, pp. 791-799, 2008.

[77] R. Mathew, "Inflammation and pulmonary hypertension," Cardiology in Review, vol. 18, no. 2, pp. 67-72, 2010.

[78] M. Debidda, L. Wang, H. Zang, V. Poli, and Y. Zheng, "A role of STAT3 in Rho GTPase-regulated cell migration and proliferation," The Journal of Biological Chemistry, vol. 280, no. 17, pp. 17275-17285, 2005.

[79] J. F. Jasmin, I. Mercier, F. Sotgia, and M. P. Lisanti, "SOCS proteins and caveolin-1 as negative regulators of endocrine signaling," Trends in Endocrinology and Metabolism, vol. 17, no. 4, pp. 150-158, 2006.

[80] J. Huang, P. M. Kaminski, J. G. Edwards et al., "Pyrrolidine dithiocarbamate restores endothelial cell membrane integrity and attenuates monocrotaline-induced pulmonary artery hypertension," American Journal of Physiology, vol. 294, no. 6, pp. L1250-L1259, 2008.

[81] J. F. Jasmin, I. Mercier, J. Dupuis, H. B. Tanowitz, and M. P. Lisanti, "Short-term administration of a cellpermeable caveolin-1 peptide prevents the development of monocrotaline-induced pulmonary hypertension and right ventricular hypertrophy," Circulation, vol. 114, no. 9, pp. 912-920, 2006.

[82] R. Mathew, J. Huang, and M. H. Gewitz, "Pulmonary artery hypertension: caveolin-1 and eNOS interrelationship: a new perspective," Cardiology in Review, vol. 15, no. 3, pp. 143149, 2007.

[83] B. Razani, X. B. Wang, J. A. Engelman et al., "Caveolin-2deficient mice show evidence of severe pulmonary dysfunction without disruption of caveolae," Molecular and Cellular Biology, vol. 22, no. 7, pp. 2329-2344, 2002.

[84] J. A. Barberà, V. I. Peinado, and S. Santos, "Pulmonary hypertension in chronic obstructive pulmonary disease," 
European Respiratory Journal, vol. 21, no. 5, pp. 892-905, 2003.

[85] T. Murata, K. Sato, M. Hori, H. Ozaki, and H. Karaki, "Decreased endothelial nitric-oxide synthase (eNOS) activity resulting from abnormal interaction between eNOS and its regulatory proteins in hypoxia-induced pulmonary hypertension," The Journal of Biological Chemistry, vol. 277, no. 46, pp. 44085-44092, 2002.

[86] S. Adnot, B. Raffestin, S. Eddahibi, P. Braquet, and P. E. Chabrier, "Loss of endothelium-dependent relaxant activity in the pulmonary circulation of rats exposed to chronic hypoxia," Journal of Clinical Investigation, vol. 87, no. 1, pp. 155-162, 1991.

[87] R. Mathew, N. Yuan, L. Rosenfeld, M. H. Gewitz, and A. Kumar, "Effects of monocrotaline on endothelial nitric oxide synthase expression and sulfhydryl levels in rat lungs," Heart Disease, vol. 4, no. 3, pp. 152-158, 2002.

[88] J. Liu, Y. Gao, S. Negash, L. D. Longo, and J. U. Raj, "Longterm effects of prenatal hypoxia on endothelium-dependent relaxation responses in pulmonary arteries of adult sheep," American Journal of Physiology, vol. 296, no. 3, pp. L547L554, 2009.

[89] R. Mathew, J. Huang, X. Zhao et al., "Activation of signal transducer and transcription of (STAT) 3 in hypoxia-induced pulmonary hypertension," The FASEB Journal, vol. 21, p. A1435, abstract, 2007.

[90] K. Schultz, B. L. Fanburg, and D. Beasley, "Hypoxia and hypoxia-inducible factor- $1 \alpha$ promote growth factor-induced proliferation of human vascular smooth muscle cells," American Journal of Physiology, vol. 290, no. 6, pp. H2528-H2534, 2006.

[91] J. E. Jung, H. G. Lee, IK. H. Cho et al., "STAT3 is a potential modulator of HIF-1-mediated VEGF expression in human renal carcinoma cells," The FASEB Journal, vol. 19, no. 10, pp. 1296-1298, 2005.

[92] Q. Xu, J. Briggs, S. Park et al., “Targeting Stat3 blocks both HIF-1 and VEGF expression induced by multiple oncogenic growth signaling pathways," Oncogene, vol. 24, no. 36, pp. 5552-5560, 2005.

[93] T. Murata, K. Kinoshita, M. Hori et al., "Statin protects endothelial nitric oxide synthase activity in hypoxia-induced pulmonary hypertension," Arteriosclerosis, Thrombosis, and Vascular Biology, vol. 25, no. 11, pp. 2335-2342, 2005.

[94] B. M. Ewenstein, M. J. Warhol, R. I. Handin, and J. S. Pober, "Composition of the von Willebrand factor storage organelle (Weibel-Palade body) isolated from cultured human umbilical vein endothelial cells," Journal of Cell Biology, vol. 104, no. 5, pp. 1423-1433, 1987.

[95] S. M. Kawut, E. M. Horn, K. K. Berekashvili, A. C. Widlitz, E. B. Rosenzweig, and R. J. Barst, "von Willebrand factor independently predicts long-term survival in patients with pulmonary arterial hypertension," Chest, vol. 128, no. 4, pp. 2355-2362, 2005.

[96] S. Sakao, L. Taraseviciene-Stewart, J. D. Lee, K. Wood, C. D. Cool, and N. F. Voelkel, "Initial apoptosis is followed by increased proliferation of apoptosis-resistant endothelial cells," The FASEB Journal, vol. 19, no. 9, pp. 1178-1180, 2005.

[97] G. Gabella and D. Blundell, "Effect of stretch and contraction on caveolae of smooth muscle cells," Cell and Tissue Research, vol. 190, no. 2, pp. 255-271, 1978.

[98] L. C. Huber, A. Soltermann, M. Fischler et al., "Caveolin1 expression and hemodynamics in COPD patients," Open Respiratory Medicine Journal, vol. 3, pp. 73-78, 2009.
[99] J. Thyberg, "Caveolin-1 and caveolae act as regulators of mitogenic signaling in vascular smooth muscle cells," Arteriosclerosis, Thrombosis, and Vascular Biology, vol. 23, no. 9, pp. 1481-1483, 2003.

[100] J.-I. Kawabe, S. Okumura, M.-C. Lee, J. Sadoshima, and Y. Ishikawa, "Translocation of caveolin regulates stretchinduced ERK activity in vascular smooth muscle cells," American Journal of Physiology, vol. 286, no. 5, pp. H1845H1852, 2004.

[101] D. G. Sedding and R. C. Braun-Dullaeus, "Caveolin-1: dual role for proliferation of vascular smooth muscle cells," Trends in Cardiovascular Medicine, vol. 16, no. 2, pp. 50-55, 2006.

[102] M. M. Hill, M. Bastiani, R. Luetterforst et al., "PTRFcavin, a conserved cytoplasmic protein required for caveola formation and function," Cell, vol. 132, no. 1, pp. 113-124, 2008.

[103] B. Sinha, D. Köster, R. Ruez et al., "Cells respond to mechanical stress by rapid disassembly of caveolae," Cell, vol. 144, no. 3, pp. 402-413, 2011.

[104] B. Annabi, M. Lachambre, N. P. Bousquet-Gagnon, M. Pagé, D. Gingras, and R. Béliveau, "Localization of membrane-type 1 matrix metalloproteinase in caveolae membrane domains," Biochemical Journal, vol. 353, no. 3, pp. 547-553, 2001.

[105] A. C. Newby, "Matrix metalloproteinases regulate migration, proliferation, and death of vascular smooth muscle cells by degrading matrix and non-matrix substrates," Cardiovascular Research, vol. 69, no. 3, pp. 614-624, 2006.

[106] R. R. Pauly, A. Passaniti, C. Bilato et al., "Migration of cultured vascular smooth muscle cells through a basement membrane barrier requires type IV collagenase activity and is inhibited by cellular differentiation," Circulation Research, vol. 75, no. 1, pp. 41-54, 1994.

[107] T. M. Williams, F. Medina, I. Badano et al., "Caveolin1 gene disruption promotes mammary tumorigenesis and dramatically enhances lung metastasis in vivo: role of Cav1 in cell invasiveness and matrix metalloproteinase (MMP2/9) secretion," The Journal of Biological Chemistry, vol. 279, no. 49, pp. 51630-51646, 2004.

[108] J. W. Wertz and P. M. Bauer, "Caveolin-1 regulates BMPRII localization and signaling in vascular smooth muscle cells," Biochemical and Biophysical Research Communications, vol. 375, no. 4, pp. 557-561, 2008.

[109] M. Beiderlinden, H. Kuehl, T. Boes, and J. Peters, "Prevalence of pulmonary hypertension associated with severe acute respiratory distress syndrome: predictive value of computed tomography," Intensive Care Medicine, vol. 32, no. 6, pp. 852857, 2006.

[110] S. Saharan, R. Lodha, and S. K. Kabra, "Management of acute lung injury/ARDS," Indian Journal of Pediatrics, vol. 77, no. 11, pp. 1296-1302, 2010.

[111] M. A. Matthay and R. L. Zemans, "The acute respiratory distress syndrome: pathogenesis and treatment," Annual Review of Pathology, vol. 6, pp. 147-163, 2011.

[112] L. B. Ware, E. R. Conner, and M. A. Matthay, "von Willebrand factor antigen is an independent marker of poor outcome in patients with early acute lung injury," Critical Care Medicine, vol. 29, no. 12, pp. 2325-2331, 2001.

[113] R. Gosens, G. L. Stelmack, St. Bos et al., "Caveolin-1 is required for contractile phenotype expression by airway smooth muscle cells," Journal of Cellular and Molecular Medicine. In press.

[114] R. Gosens, G. L. Stelmack, G. Dueck et al., "Role of caveolin1 in p42/p44 MAP kinase activation and proliferation 
of human airway smooth muscle," American Journal of Physiology, vol. 291, no. 3, pp. L523-L534, 2006.

[115] G. S. Hassan, T. M. Williams, P. G. Frank, and M. P. Lisanti, "Caveolin-1-deficient aortic smooth muscle cells show cell autonomous abnormalities in proliferation, migration, and endothelin-based signal transduction," American Journal of Physiology, vol. 290, no. 6, pp. H2393-H2401, 2006.

[116] B. Razani, J. A. Engelman, X. B. Wang et al., "Caveolin-1 null mice are viable but show evidence of hyperproliferative and vascular abnormalities," The Journal of Biological Chemistry, vol. 276, no. 41, pp. 38121-38138, 2001.

[117] D. S. Park, A. W. Cohen, P. G. Frank et al., "Caveolin-1 null (/-) mice show dramatic reductions in life span," Biochemistry, vol. 42, no. 51, pp. 15124-15131, 2003.

[118] M. Drab, P. Verkade, M. Elger et al., "Loss of caveolae, vascular dysfunction, and pulmonary defects in caveolin-1 gene-disrupted mice," Science, vol. 293, no. 5539, pp. 24492452, 2001.

[119] Y. Y. Zhao, Y. Liu, R. V. Stan et al., "Defects in caveolin-1 cause dilated cardiomyopathy and pulmonary hypertension in knockout mice," Proceedings of the National Academy of Sciences of the United States of America, vol. 99, no. 17, pp. 11375-11380, 2002.

[120] J. Liu, P. Lee, F. Galbiati, R. N. Kitsis, and M. P. Lisanti, "Caveolin-1 expression sensitizes fibroblastic and epithelial cells to apoptotic stimulation," American Journal of Physiology, vol. 280, no. 4, pp. C823-C835, 2001.

[121] T. Murata, M. I. Lin, Y. Huang et al., "Reexpression of caveolin-1 in endothelium rescues the vascular, cardiac, and pulmonary defects in global caveolin-1 knockout mice," Journal of Experimental Medicine, vol. 204, no. 10, pp. 23732382, 2007.

[122] R. C. Tyler, M. Muramatsu, S. H. Abman et al., "Variable expression of endothelial no synthase in three forms of rat pulmonary hypertension," American Journal of Physiology, vol. 276, no. 2, pp. L297-L303, 1999.

[123] Y.-Y. Zhao, Y. D. Zhao, M. K. Mirza et al., "Persistent eNOS activation secondary to caveolin-1 deficiency induces pulmonary hypertension in mice and humans through PKG nitration," Journal of Clinical Investigation, vol. 119, no. 7, pp. 2009-2018, 2009.

[124] N. A. Mason, D. R. Springall, M. Burke et al., "High expression of endothelial nitric oxide synthase in plexiform lesions of pulmonary hypertension," Journal of Pathology, vol. 185, no. 3, pp. 313-318, 1998.

[125] A. Giaid and D. Saleh, "Reduced expression of endothelial nitric oxide synthase in the lungs of patients with pulmonary hypertension," The New England Journal of Medicine, vol. 333, no. 4, pp. 214-221, 1995.

[126] R. K. Gupta and P. Vaideeswar, "Nitric oxide synthase 3 and endothelin 1 immunoreactivity in pulmonary hypertension," Indian Journal of Pathology \& Microbiology, vol. 53, no. 3, pp. 447-450, 2010.

[127] B. S. Zuckerbraun, P. George, and M. T. Gladwin, "Nitrite in pulmonary arterial hypertension: therapeutic avenues in the setting of dysregulated arginine/nitric oxide synthase signalling," Cardiovascular Research, vol. 89, no. 3, pp. 542$552,2011$.

[128] R. Mathew, N. Y. T. Fan, N. Yuan, P. N. Chander, M. H. Gewitz, and C. T. Stier, "Inhibition of NOS enhances pulmonary vascular changes in stroke-prone spontaneously hypertensive rats," American Journal of Physiology, vol. 278, no. 1, pp. L81-L89, 2000.
[129] E. Burgermeister, M. Liscovitch, C. Röcken, R. M. Schmid, and M. P. A. Ebert, "Caveats of caveolin-1 in cancer progression,” Cancer Letters, vol. 268, no. 2, pp. 187-201, 2008.

[130] A. F. G. Quest, J. L. Gutierrez-Pajares, and V. A. Torres, "Caveolin-1: an ambiguous partner in cell signalling and cancer," Journal of Cellular and Molecular Medicine, vol. 12, no. 4, pp. 1130-1150, 2008.

[131] C. Trimmer, D. Whitaker-Menezes, G. Bonuccelli et al., "CAV1 inhibits metastatic potential in melanomas through suppression of the integrin/Src/FAK signaling pathway," Cancer Research, vol. 70, no. 19, pp. 7489-7499, 2010. 


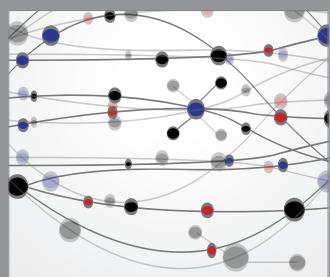

The Scientific World Journal
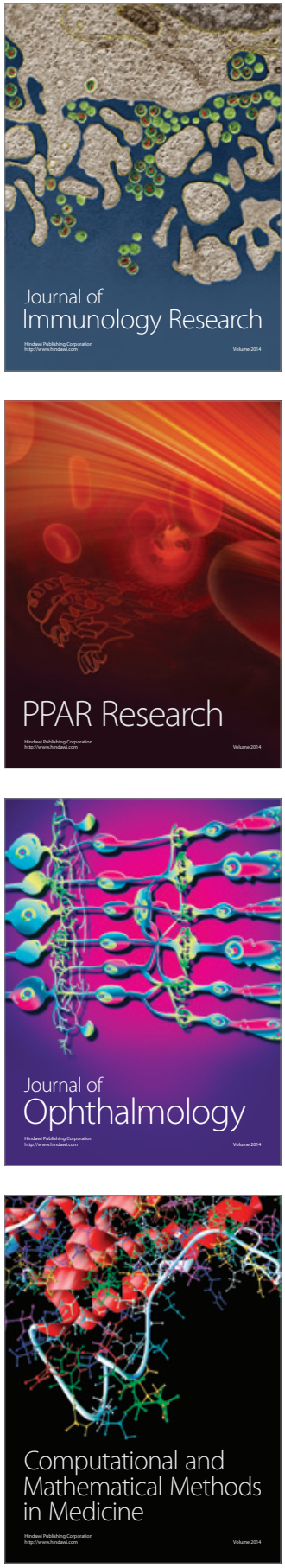

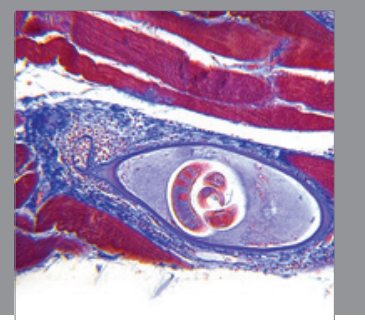

Gastroenterology

Research and Practice
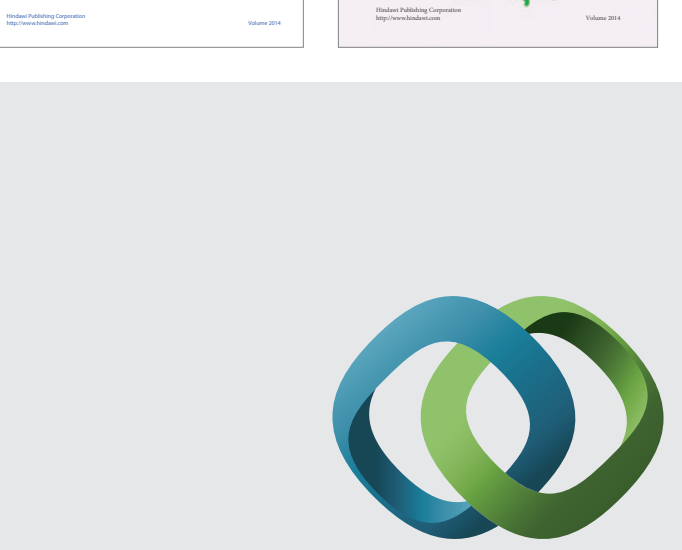

\section{Hindawi}

Submit your manuscripts at

http://www.hindawi.com
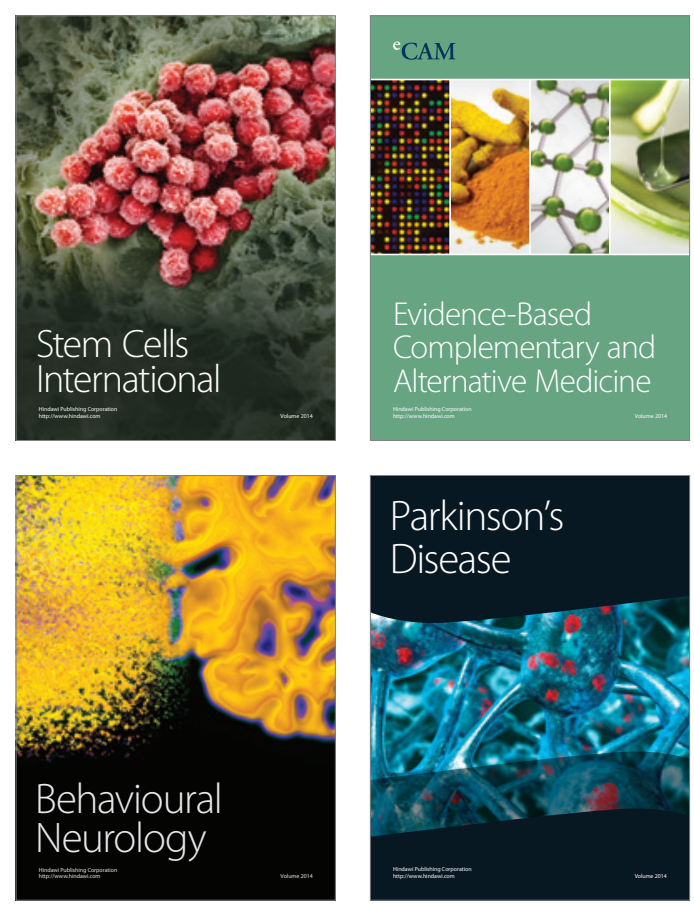

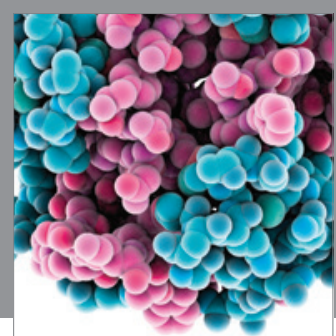

Journal of
Diabetes Research

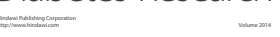

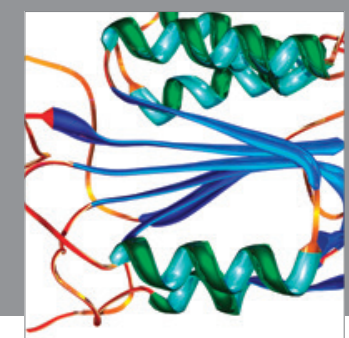

Disease Markers
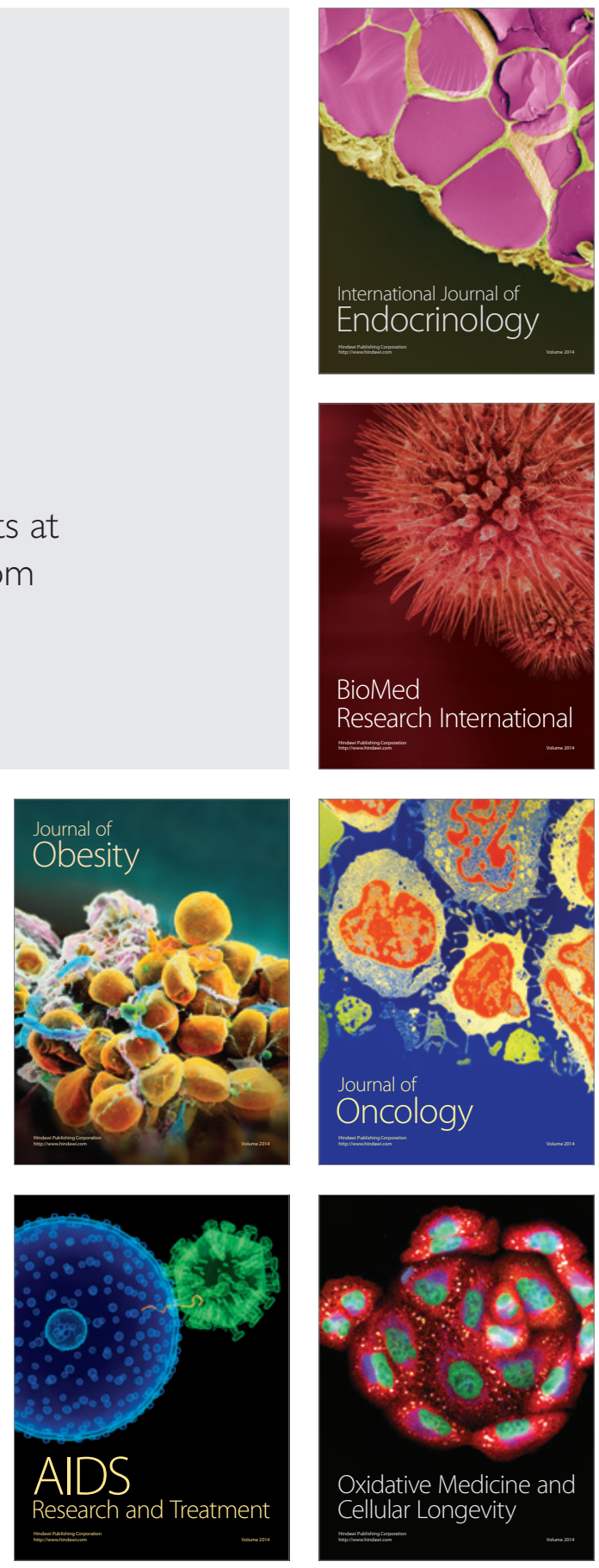